\title{
Clinical Decision-making in Speech-Language Pathology Graduate Students: Quantitative Findings
}

Carol C. Dudding

James Madison University, duddincc@jmu.edu

Danika L. Pfeiffer

James Madison University, dipalmdl@dukes.jmu.edu

DOI: doi.org/10.30707/TLCSD2.1Dudding

Follow this and additional works at: https://ir.library.illinoisstate.edu/tlcsd

Part of the Scholarship of Teaching and Learning Commons, and the Speech Pathology and Audiology Commons

\section{Recommended Citation}

Dudding, Carol C. and Pfeiffer, Danika L. (2018) "Clinical Decision-making in Speech-Language Pathology Graduate Students: Quantitative Findings," Teaching and Learning in Communication Sciences \& Disorders: Vol. 2: Iss. 1, Article 2.

DOI: doi.org/10.30707/TLCSD2.1Dudding

Available at: https://ir.library.illinoisstate.edu/tlcsd/vol2/iss1/2

This Scholarship of Teaching and Learning Research is brought to you for free and open access by ISU ReD: Research and eData. It has been accepted for inclusion in Teaching and Learning in Communication Sciences \& Disorders by an authorized editor of ISU ReD: Research and eData. For more information, please contact ISUReD@ilstu.edu. 


\title{
Clinical Decision-making in Speech-Language Pathology Graduate Students: Quantitative Findings
}

\begin{abstract}
Clinicians' decision-making skills are the foundation for the development and implementation of evidence-based practice to provide high quality clinical care. It is proposed that these skills are a result of hands-on clinical experiences (Crebbin, Beasley, \& Watters, 2013). Yet some researchers contend that the development of clinical decision-making skills requires direct instruction in critical thinking (Abrami et al., 2011; Finn, 2011). The aim of this study was to explore if and when clinical decision-making processes of speech-language pathology (SLP) students change during graduate study. Web-based case simulations were used to elicit and measure clinical decision-making in eight graduate students at three stages in their training. Participants were evaluated on four clinical tasks including (a) formulation of hypothesis, (b) selection of appropriate evaluation instruments, (c) diagnosis, (d) recommendations for therapy. Quantitative analysis revealed limited changes in SLP graduate students' clinical decision-making skills over their course of study, as a result of clinical experiences. Participants did not demonstrate change in the skill areas of forming hypotheses and selecting appropriate evaluation measures. However, they did become more accurate in identifying a correct speech-language diagnosis. This study suggests critical thinking, a necessary process for developing clinical decision-making, cannot be an assumed outcome of graduate training programs.
\end{abstract}

\section{Keywords}

clinical decision-making, simulations, clinical reasoning, diagnostic reasoning, critical thinking, speechlanguage pathology, evidence-based practice 
Clinical decision-making, a product of critical thinking, is defined as a "contextual, continuous, and evolving process," where data are "gathered, interpreted, and evaluated" in order to make an evidence-based decision (Tiffen, Corbridge, \& Slimmer, 2014, p. 401). Practicing clinicians are continually engaged in the decision-making process as they perform differential diagnosis and provide treatment to persons with communication disorders. Indeed, clinicians' decision-making skills are the foundation for the development and implementation of high quality clinical care (American Speech-Language-Hearing Association [ASHA], 2005).

Although the assumption has been that degree-seeking students will develop clinical decisionmaking abilities on their own, through coursework and clinical experiences, (Arum \& Roksa, 2010; Crebbin, Beasley, \& Watters, 2013), research suggests more explicit instruction is needed for novice clinicians to develop these skills (Ginsberg, Friberg \& Visconti, 2016). While 99\% of faculty endorse teaching critical thinking as an important goal of university education, a survey of public and private colleges and universities found that as few as $9 \%$ of instructors felt they taught critical thinking on a regular basis (Abrami, et al., 2015; DeAngelo, 2009). In response, Finn (2011) suggested requiring the critical thinking to be taught in professional training programs, declaring it a core skill of $21^{\text {st }}$ century education. As Abrambi et al. explained, students are more likely to learn how to think critically when they are taught the skills directly.

\section{Literature Review}

Experts and Novices: Knowing More, Knowing Differently. Research has long identified differences in clinical-decision making between experts and novices (Coderre, Mandin, Harasym, \& Fick, 2003; Crebbin, et al., 2013; Ginsberg, et al., 2016; Norman, 2005; Tschikota, 1993). Evans and Gadd (1989) asserted that experts in a given field of study not only know more in a given situation, but they also know differently; having internalized strategies to manage and evaluate information. Novices, on the other hand, require more exposure and explicit training to master thinking and action strategies. Tschikota (1993) published a clinical decision-making study of 19 nursing students. The findings showed that these novices, senior diploma nursing students, assigned equal importance to all pieces of data and made decisions based on factual information rather than hypotheses. Tschikota found, due to limited experience, novice nurses in the study processed information serially and in small amounts, relying on theories instead of schemas or patterns to help them select and use data in making decisions.

Another recognizable difference between a novice and an expert is the faster speed and greater fluidity of thinking; a result of pattern recognition that draws on previously stored schematic representations. Experts use these patterns to make clinical decisions, eliminating the need to analyze each step and component as novices often do (Coderre, et al., 2003; Crebbin, et al., 2013). Further, advanced decision-making processes allow clinicians to work more efficiently in fastpaced clinical environments (Crebbin, et al., 2013).

In the field of speech-language pathology, studies of novice clinicians suggest similar trends. Hill, Davidson, and Theodoros (2012) found that novice speech-language pathology students demonstrated reflective skills focused on the process and content of clinical experiences; few students showed characteristics of deeper, more critical reflectors, such as considering the patient 
perspective and noting changes in their own perspectives. Ginsberg and colleagues (2016) employed a qualitative methodology to explore the thought processes of 15 SLPs with at least five years of experience and 15 novice speech-language pathology graduate students. The aim of the study was to identify the thinking strategies, or heuristics, used in diagnostic reasoning between these two groups. The results showed that experienced clinicians were more likely to engage in higher-order planning of specific assessment hierarchies, develop contingency plans for the assessment process, and make connections between the assessment process and treatment planning. These processes show that the experienced clinicians in the study were able to prepare for evaluations more efficiently and foresee how the evaluations would impact future treatment goals. The experienced clinicians engaged in the diagnostic process more holistically, using past experiences to prepare and implement the evaluation process. According to Ginsberg and colleagues, modeling connections between assessment data and implications for treatment is crucial to the development of diagnostic reasoning skills. With this insight, training programs can begin to implement intentional teaching practices that will foster development of prototypes and schemas for graduate students.

A Continuum of Development. In medical literature, the highest outcome of refined critical thinking, having the ability to make clinical decisions, is often described as a continuum (Arocha \& Patel, 1995; Banning, 2008; Crebbin, et al., 2013). At one end of the continuum, novice clinicians rely most heavily on a slow, analytical and deductive approach for making decisions because of their lack of experience. At the other end, experienced clinicians have the ability to recognize similarities and familiar patterns in a fast and frugal process, requiring little mental energy and less time (Crebbin, et al., 2013). Furze and colleagues (2005) described a gradual developmental process of clinical reasoning among students. Physical therapy students with beginner level clinical reasoning skills demonstrated a focus on self, compartmentalized thinking, and limited acceptance of responsibility. At this early stage in development, students viewed each piece of information about a patient as being disconnected from other pieces making it difficult to select and synthesize important data. Over time, students in the Furze et al. study began to incorporate information from the patient into their clinical reasoning. In their last semester of study, they demonstrated dynamic patient interaction and integrated situational awareness. At this stage, the students began relating to the patient's background, integrating patient information into care plans, and modifying their interventions around the patient's needs. Furze et al. found students in this advanced stage of the development process were flexible and able to change directions during evaluations based on interactions with patients, suggesting a higher level of clinical decision-making abilities. Students at this stage of training began to see the client and his plan of care more holistically, moving away from their initial view of clients as segmented parts and pieces. Similar patterns of development have been identified by researchers in the fields of medicine and nursing (Arocha \& Patel, 1995; Banning, 2008).

These findings have implications for teaching clinical decision-making skills to novice clinicians. Research literature suggested that exposure to knowledge, skills and strategies is not sufficient for the development of clinical decision-making (Crebbin, et al., 2013; Norman, 2005). It requires a variety of clinical experiences and "the opportunity for deliberate practice with multiple examples and feedback, to facilitate effective transfer of basic concepts" (Norman, 2015, p. 425). This suggests the necessity of hands-on clinical experiences to foster the development of students' 
clinical decision-making skills.

Purpose of the Study. Based on the previously discussed research, students in health professions demonstrate differences in clinical decision-making as compared to experts (Crebbin, et al., 2013; Ginsberg, et al., 2016). These skills appear to develop over time (Arocha \& Patel, 1995; Banning, 2008; Crebbin, et al., 2013; Furze, et al., 2015). It is proposed that these changes occur as a result of hands-on clinical experiences (Crebbin, et al., 2013; Norman, 2005). Yet some researchers contend that the development of clinical decision-making skills requires direct instruction in critical thinking (Abrami, et al., 2011; Finn, 2011).

The current study serves as an exploratory examination of the types of changes in clinical decisionmaking specific to (a) formulation of hypothesis, (b) selection of appropriate evaluation instruments, (c) diagnosis, and (d) recommendations for therapy that occurred in a group of graduate speech-language pathology students, enrolled in academic and clinical coursework and practica, without direct instruction in critical thinking. Results will serve to guide future research in students' development of clinical decision-making skills in graduate speech-language pathology programs.

This study examines the following research questions:

1. Do speech-language pathology graduate students demonstrate changes in diagnostic clinical decision-making as they gain clinical experiences?

2. If so, which specific diagnostic clinical decision-making skills evidence change?

It was hypothesized that clinical decision-making skills would change over the course of study as a result of didactic academic coursework and supervised clinical practica experiences; without direct instruction in critical thinking. It was expected that students would require less time to complete case studies. It was further hypothesized that students would demonstrate changes in clinical decision-making across the four diagnostic skills examined.

\section{Method}

Participants. Recruitment of participants was conducted with approval of the Internal Review Board (IRB) at James Madison University (JMU). Participants were recruited from a convenience sample consisting of 22 first year students enrolled in a five-semester speech-language pathology graduate program at JMU; the program is accredited by the American Speech-Language-Hearing Association (ASHA). A total of 11 students (50\%) participated in this study following submission of informed consent. Participation was voluntary. Participants had the opportunity to win a gift card in the amount of $\$ 25$ for completion of each case, but no other compensation was offered. In accordance with the JMU IRB protocol, the researcher was not permitted to recruit students. A research assistant, a peer of the participants, conducted recruitment activities, which may have been a factor in the limited participation. Additionally, it is suspected that the commitment to participate over three semesters may have limited participation.

While 11 participants started the study, only eight participants (73\%) completed both the survey 
and case study portions of the study at all three stages and were included in data analysis. Of the three participants who did not complete the study, one completed only the initial case and survey and two additional participants failed to complete the final case and/or survey.

Because of a lack in male enrollment, all eight participants were female; a representative demographic of the communication sciences and disorders field. At the initial time of the study, participants completed 27 credit hours of graduate level coursework with grade point averages (GPAs) ranging from 3.30 to 3.94 on a four-point scale $(M=3.66, S D=.19)$. Directly related to the study, students had completed three graduate courses (nine credit hours) in child language disorders, child phonological disorders and phonetics. At the start of the study, the total number of clinical hours completed by the participants in the university clinic ranged from zero to 61 ( $M$ $=45, S D=20.5)$, and the number of child assessment hours ranged from zero to $30(M=13, S D$ $=9.9)$.

Measures. Case Simulations. Participants were required to complete a total of three web-based pediatric case simulations created for this study. One simulated case was of a child with an articulation disorder, one with a phonological disorder, and the other with typical speech and language. The web-based case simulations were developed, housed and accessed by participants through DecisionSim, a hosted, secure software service that allows for the creation of multi-media simulations. Each student participating in this study was assigned a unique username and password to the DecisionSim website. Once logged into the case simulation, students were given a comprehensive case history of a patient: the reason for referral, background information, a video example of connected speech, and test results. DecisionSim recorded the number of steps and time in seconds required to complete each case.

Participants were then asked to provide text-based input on a series of questions related to the simulation. The prompts were as follows:

1. Identify the three most important pieces of information (free response).

2. Identify initial impressions (free response).

3. Select tests to administer to the patient (multiple choice).

4. Select a diagnosis (multiple choice).

5. Make recommendation for treatment (yes, no).

6. Determine referrals needed (multiple choice).

7. Create treatment goals (free response).

These prompts were identified from requisite knowledge and skills in the area of evaluation as outlined in Standard V-B of ASHA's 2014 Standards for Certificate of Clinical Competence in Speech-Language Pathology (Council for Clinical Certification in Audiology and SpeechLanguage Pathology of the American Speech-Language-Hearing Association, 2013).

The case simulations were parallel in complexity and structure. All three cases were built employing identical branching and node structures. That is, all cases presented information and prompts in identical manner. A post hoc analysis of overall student accuracy and seconds per step to complete cases suggested equivalency of cases $(M=42, S D=7.22, M=153, S D=31$; respectively). To determine accuracy of responses, five clinical educators with at least five years 
of clinical experience, completed each of the cases online and provided answers to each prompt. A research assistant compiled the responses. The researcher and clinical educators met as a group to discuss each set of responses. Correct responses for each of the cases were determined by groupconsensus method; that is all clinical educators were in agreement in order for a response to be deemed correct.

Online Survey. The students who participated in this study were also required to complete an online survey providing the following information: their academic status (GPA), number of completed direct clinical hours, coursework completed, and confidence levels in their knowledge and skills in the area of assessment outlined in ASHA's 2014 Standards for Certificate in SpeechLanguage Clinical Competence in Speech-Language Pathology. The survey required a four-point Likert scale response indicating level of confidence (i.e., self-efficacy) in each of the 21 clinical skills presented. Participants completed the survey at the initiation of each case simulation, for a total of three times. The purpose of the online survey was to probe for factors that might account for changes in clinical decision-making.

Research Design. Participants completed two measures (case simulation and online survey) at three stages in their five-semester graduate program. The first stage occurred after completion of the first semester of coursework, which included graduate level courses in phonological disorders, child language disorders, and the diagnostic process. The students had also completed their first clinical assignment in the university clinic with an average of 45 clinical hours $(S D=20.5)$. The second set of data was obtained after the completion of three semesters of graduate study. At this point in the program, students had completed $79 \%$ of coursework and three practica at the university clinic. At this stage, participants reported a mean GPA of $3.60(S D=.18)$ and ranged in clinical hours from 54 to $171(M=114, S D=38)$. The third set of data was completed after the fourth semester of graduate coursework; this stage followed completion of all coursework, as well as, an off-campus clinical practica (three or four days per week). At this time, students reported an average GPA of $3.70(S D=.14)$ and ranged from 115 to 356 clinical hours $(M=273, S D=74.60)$. This time frame was determined to be the final data point because the researchers were concerned that students, enrolled full-time in off-campus placements, distanced from the program and close to graduation would not elect to participate in the final phase of this project if it were extended to the end of the final semester.

The order of case simulation completion (i.e., a child with an articulation disorder, one with a phonological disorder, and the other with typical speech and language) was randomized across participants. Participants were instructed to complete the DecisionSim simulated case and online survey at a time and location convenient to them within a given two-week period.

\section{Results}

Quantitative analysis $(n=8)$ of the time in seconds and number of steps taken to complete the case, as well as the accuracy of responses as compared to experts, was undertaken to identify changes in graduate students' clinical decision-making. As shown in Table 1, there was no significant difference in the number of steps participants took to complete the initial case versus the final case; $t(7)=2.04, p=.08$. 
Table 1

Steps required to complete case by case order $(n=8)$

Total number of steps

\begin{tabular}{lccc} 
Case Order & $M$ & $S D$ & SE \\
1 & 22.38 & 3.07 & 1.09 \\
2 & 21.00 & 0.93 & 0.33 \\
3 & 20.37 & 1.19 & 0.42 \\
\hline
\end{tabular}

The lack of significant changes in the number of steps to complete the cases may be an artifact of the design of the case simulation, in that each student was required to complete all prompts within the cases. Only students who went back in the case to review earlier findings would evidence a difference in the number of steps.

As shown in Table 2, comparison of the means of the amount of time required to complete the first versus last case failed to reveal significant differences; $t(7)=.47, p=.65$. This finding may have been due to small sample size. When examining continuous data, there was a large significant positive correlation between the time required to complete the first and last case; $r(6)=.87, p<.05$. As hypothesized, students required less time to complete the cases over the course of the study. Analysis of the relationship between the number of clinical hours and time in seconds to complete the final case study revealed no significant correlation; $r(6)=.28, p=.25$. Failure to identify a significant relationship between the number of clinical hours and time to complete the cases may be attributed to a small sample size.

Table 2

Time in seconds to complete first and last case $(n=8)$

Time (s)

\begin{tabular}{lccc}
\cline { 2 - 3 } Case Order & $M$ & $S D$ & SE \\
\hline 1 & 4700.50 & 2335.22 & 825.63 \\
3 & 4255.90 & 4432.91 & 1567.27 \\
\hline
\end{tabular}

Item responses of students were compared to the responses of expert clinicians to determine the accuracy of the clinical decisions participants made during the case simulations. As shown in Table 
3, four categories were measured including (a) formulation of hypothesis; (b) selection of evaluation instruments; (c) diagnosis; (d) recommendations for therapy.

Table 3

Percentage of Agreement with Experts by Chronological Case Order by Task $(n=8)$

\begin{tabular}{lcccc} 
Case order & $\begin{array}{c}\text { Hypothesis } \\
\text { (free } \\
\text { response) }\end{array}$ & $\begin{array}{c}\text { Evaluation } \\
\text { instruments } \\
\text { (multiple } \\
\text { choice) }\end{array}$ & $\begin{array}{c}\text { Diagnosis } \\
\text { (multiple } \\
\text { choice) }\end{array}$ & $\begin{array}{c}\text { Recommendations } \\
\text { for therapy } \\
\text { (yes/no) }\end{array}$ \\
\hline First Case & $25 \%$ & $78 \%$ & $13 \%$ & $50 \%$ \\
Second Case & $0 \%$ & $72 \%$ & $38 \%$ & $100 \%$ \\
Third Case & $0 \%$ & $69 \%$ & $75 \%$ & $100 \%$ \\
\hline
\end{tabular}

Note: Case order was randomized among participants.

The researchers used the clinical educators' responses as a guideline for evaluating the graduate students' accuracy on the case simulations. Results were assessed for trends across cases (first, second, third cases completed chronologically). The graduate students' responses for their hypotheses, diagnoses, and recommendations for therapy were deemed correct if they matched the clinical educators' response. When evaluating the accuracy of the students' selection of evaluation instruments, the researchers took into consideration that several combinations of assessments may be appropriate for the client. Therefore, errors in selection of evaluation instruments were characterized by including inappropriate measures (i.e. selection of a language assessment for a child who only had articulation concerns) and not errors of omission (i.e. selecting one specific articulation assessment instead of another).

Participants demonstrated little or no change in performance over time in the formulation of accurate hypotheses and the selection of appropriate evaluation instruments. Errors in formulating hypothesis were often characterized by an over-identification of problems. That is, the majority of responses included a speech and language disorder and/or delay, even if there were no indicators of language impairment in the case history. Other hypothesis offered included: developmental delay, stuttering, hearing impairment, reading problems, attention deficit disorder, and severe expressive language delay. Additionally, individual participant performance did not remain stable across cases. That is, a participant who was correct in making initial impressions in the first case may not have been accurate in her initial impressions in the second and/or third cases. The steadiest, upward trend of improvement was seen in the participants' accuracy of diagnosis. The number of participants who made an accurate diagnosis as compared to the experts increased by $62 \%$ from the first to the third case.

The last task, determining recommendations for therapy following the evaluation was the greatest strength of the participants. Initially, $50 \%$ of participants $(n=8)$ accurately decided if speech therapy was appropriate for the client. This improved to $100 \%$ of participants in both the second 
and third cases. It should be noted that this item required a dichotomous yes/no response.

Analysis of the relationships between the number of clinical hours attained and the accuracy of responses in the final study completed revealed no significant correlations (See Table 4). This may have been a result of the small sample size and the variation in clinical hours among participants.

Table 4

Correlations between accuracy and number of clinical hours of final case $(n=8)$

\begin{tabular}{lcccccc}
\hline Measure & 1 & 2 & 3 & 4 & $M$ & $S D$ \\
\hline Hours & & -.09 & .28 & -.46 & 272.75 & 74.75 \\
Hypothesis & -.06 & & .14 & .14 & 12.50 & 35.36 \\
Assessments & .74 & .143 & & -.14 & 68.75 & 17.68 \\
Diagnosis & -.45 & .14 & -.14 & & 87.59 & 35.36 \\
\hline
\end{tabular}

Note: There were no correlations significant at the .01 level (2-tailed)

To identify differences among case types, accuracy of diagnostic statements across the three types of simulated cases were examined. As shown in Table 5, the percentage of accurate diagnostic statements is similar across case type. These findings may strengthen the researchers' assertion that the cases were equivalent in complexity.

Table 5

Accuracy of Participants' Diagnostic Statements by Case Type

\begin{tabular}{lc} 
Case & Percentage of Participants with Accurate Diagnoses $(n=8)$ \\
\hline Normal Speech and & $50 \%$ \\
Language & \\
Articulation & $38 \%$ \\
Phonological & $38 \%$ \\
Disorder & \\
\hline
\end{tabular}

\section{Discussion}

Findings and results of this exploratory study should be viewed with caution given its limited sample size. The small sample size may have limited the study's ability to detect significant differences that may in fact exist (i.e., Type II error). However, trends in the data can be useful in designing further studies.

The initial findings of this study fail to support the hypothesis of the researchers that students would demonstrate changes in clinical decision-making skills as evidenced by the time and number of steps to complete case studies, and improved accuracy of responses as compared to experts. It was hypothesized that changes would occur over the course of study as a result didactic academic coursework and supervised clinical practica experiences; without direct instruction in critical thinking. This study failed to reveal a relationship between the number of clinical hours obtained in practica and accuracy in formulation of hypothesis, selection of evaluation instruments, accurate 
diagnosis, and recommendations for therapy when compared to experts. Again, the limited sample size may have resulted in no significant relationship.

Findings suggest that there is a relationship between the time required to complete a case study and the number of clinical hours obtained through practica. As is consistent with the literature (Crebbin, et al., 2013), more advanced clinicians make decisions more quickly because they recognize familiar patterns. The participants in this study may be moving along the continuum of clinical decision-making (Banning, 2008; Crebbin, et al., 2013). However, additional research is required to fully support these findings.

Students' performance was compared to experts to assess accuracy in the following areas: hypothesis formulation, selection of evaluation instruments, making a diagnosis, and recommendations for therapy. Results suggest trends worthy of further exploration. Participants failed to demonstrate development in the skill areas of forming hypotheses and selecting appropriate evaluation measures. When forming a hypothesis, participants considered a broad range of disorders that were not based on case history. This pattern of over identification of disorders is consistent with the literature describing novice clinicians' limited ability to integrate information (Arocha \& Patel, 1995; Banning, 2008; Furze et al., 2015). However, they were more accurate in identifying the correct speech-language diagnoses. This finding suggests the students in this study became more proficient over time in interpreting given test results to formulate a diagnosis; however, they did not possess the higher-level skills required to generate accurate hypotheses and select appropriate evaluation instruments. These results are similar to the findings of other researchers (Arocha \& Patel, 1995; Ginsberg, et al., 2016).

Limitations. As mentioned previously, the small sample size was a limitation of the study. Only eight students from one speech-language pathology graduate program completed the entirety of the study, which limits statistical analysis and generalization of the findings. Since this study was concluded prior to the completion of the students' final semester, they had not completed all 375 required clinical hours $(M=273, S D=74.60)$. Future studies should be extended to include the final practicum, and perhaps into the clinical fellowship.

\section{Conclusions}

This study offers insights into the decision-making process of graduate speech-language pathology students. In light of the preliminary findings and with consideration of limitations of this study, this study supports other researchers in concluding that educators cannot assume future clinicians will learn how to think critically solely as a result of their academic and clinical experiences. As Finn (2011) suggests, the most direct way to learn critical thinking and understand its relevance for evidence-based practice is to teach it early when clinicians are students in training programs. Some researchers claim critical thinking should be viewed as a goal and not a by-product of learning (Kamhi, 2011).

In addition, preliminary results suggest that selecting appropriate diagnosis and making recommendations for treatment services are relative strengths for speech-language pathology graduate students. Findings suggest that formulation of a hypothesis (i.e., initial impressions) and 
selection of appropriate evaluation measures are appropriate targets for direct instruction. This study also demonstrates the potential of simulated cases as an authentic and valid measure of student clinical performance. When designing future studies, matching students by the number of clinical hours completed should be considered, to control for differences in clinical experiences. Studies comparing the performance of students with and without direct instruction in decisionmaking would also add to the current body of research in this area.

By strengthening the critical thinking abilities of our future clinicians, we provide them with the tools necessary to develop the most effective and efficient services. This allows speech-language pathology to remain a relevant and vital service provider within ever changing healthcare and educational environments. Further research to identify effective means of developing critical thinking in graduate speech-language pathology students is necessary.

\section{References}

Abrami, P. C., Bernard, R. M., Borokhovski, E., Waddington, D. I., Wade, C. A., \& Persson, T. (2015). Strategies for teaching students to think critically: A meta-analysis. Review of Educational Research, 85(2), 275-314.

American Speech-Language-Hearing Association. (2005). Evidence-based practice in communication disorders [Position Statement]. Retrieved from: http://www.asha.org/policy/PS2005-00221/

Arocha, J. F. \& Patel, V. L. (1995). Novice diagnostic reasoning in medicine: accounting for evidence. The Journal of the Learning Sciences, 4(4), 355-384.

Arum, R., \& Roksa, J. (2010). Academically Adrift: Limited Learning on College Campuses. Chicago, IL: University of Chicago Press.

Banning, M. (2008). Clinical reasoning and its application to nursing: Concepts and research studies. Nurse Education in Practice, 8, 177-183. doi:10.1016/ j.nepr.2007.06.004

Council for Clinical Certification in Audiology and Speech-Language Pathology of the American Speech-Language-Hearing Association. (2013). 2014 Standards for the Certificate of Clinical Competence in Speech-Language Pathology. Retrieved from http://www.asha.org/Certification/2014-Speech-Language-Pathology-CertificationStandards/

Coderre, S., Mandin, H., Harasym, P.H., \& Fick, G.H. (2003). Diagnostic reasoning strategies and diagnostic success. Medical Education, 37, 695-703.

Crebbin, W., Beasley, S. W., \& Watters, D. A. (2013). Clinical decision-making: How surgeons do it. ANZ Journal of Surgery, 83(6), 422-428. doi: 10.1111/ans.12180

DeAngelo, L. (2009). The American College Teacher: National Norms for the 2007-2008 HERI Faculty Survey. Retrieved from https://heri.ucla.edu

Evans, D. A. \& Gadd, C. S. (1989). Managing coherence and context in medical problemsolving discourse. In D. A. Evans \& V. L. Patel (Eds.) Cognitive Science in Medicine. Cambridge, MA: The MIT Press.

Finn, P. (2011). Critical thinking: Knowledge and skills for evidence-based practice. Language, Speech and Hearing Services in Schools, 42(1), 69-72. doi: 10.1044/0161-1461

Furze, J., Black, L., Hoffman, J., Barr, J. B., Cochran, T. M., \& Jensen, G. M. (2015). Exploration of students' clinical reasoning development in professional physical therapy education. Journal of Physical Therapy Education, 29(3), 22-33. 
Ginsberg, S. M., Friberg, J. C., \& Visconti, C. F. (2016). Diagnostic reasoning by experienced speech-language pathologists and student clinicians. Contemporary Issues in Communication Science and Disorders, 43, 87-97. doi: 1092-5171/16/4301-0087

Hill, A. E., Davidson, B. J., \& Theodoros, D. G. (2012). Reflections on clinical learning in novice speech-language therapy students. International Journal of Language \& Communication Disorders, 47(4), 413-426. doi: 10.1111/j.1460-6984.2012.00154

Kamhi, A. G. (2011). Balancing certainty and uncertainty in clinical practice. Language, Speech and Hearing in the Schools, 42, 88-93. doi:10.1044/0161-1461

Norman, G. (2005). Research in clinical reasoning: Past history and current trends. Medical Education, 39(4), 418-427.

Tiffen, J., Corbridge, S. J., \& Slimmer, L. (2014). Enhancing clinical decision-making: development of a contiguous definition and conceptual framework. Journal of Professional Nursing, 30(5), 399-405.

Tschikota, S. (1993). The clinical decision-making processes of student nurses. Journal of Nursing Education, 32(9), 389-398. 